\title{
Towards a cross-domain interoperable framework for natural hazards and disaster risk reduction information
}

\author{
Robert Tomas $^{1}$ (D) Matthew Harrison ${ }^{2} \cdot$ José I. Barredo $^{3}$. \\ Florian Thomas ${ }^{4} \cdot$ Miguel Llorente Isidro $^{5} \cdot$ Manuela Pfeiffer $^{6}$ • \\ Otakar Črba ${ }^{7}$
}

Received: 7 November 2014/ Accepted: 1 May 2015/Published online: 21 May 2015

(C) The Author(s) 2015. This article is published with open access at Springerlink.com

\begin{abstract}
According to the United Nations' International Strategy for Disaster Reduction, "natural hazards are processes or phenomena that may cause loss of life, injury or other health impacts, property damage, loss of livelihoods and services, social and economic disruption, or environmental damage". They are at the interface between human and natural systems. From this perspective, natural hazards are a multidimensional domain including environmental issues, the private and public sector and citizens and governance ranging from local to supranational. The vast amount of information and data necessary for comprehensive hazard and risk assessment present many challenges regarding the lack of accessibility, comparability, quality, organisation and dissemination of natural hazards spatial data. In order to mitigate these limitations, an interoperability framework has been developed and published in the INSPIRE Data Specification on Natural Risk Zonestechnical guidelines (DS) document. This framework provides means for facilitating access, integration, harmonisation and dissemination of natural hazard data from different domains and sources. The objective of this paper is twofold. Firstly, the paper highlights
\end{abstract}

Robert Tomas

robert.tomas@jrc.ec.europa.eu

1 European Commission, Joint Research Centre, Institute for Environment and Sustainability, Digital Earth and Reference Data Unit, Via Fermi 2749, 21027 Ispra, Italy

2 British Geological Survey, Keyworth, Nottingham NG12 5GG, UK

3 European Commission, Joint Research Centre, Institute for Environment and Sustainability, Forest Resources and Climate Unit, Via Fermi 2749, 21027 Ispra, Italy

4 National Institute of Geography and Forestry Information, 70 avenue de Paris, 94165 Saint-Mandé, France

5 Spanish Geological Survey, Area of Geological Risks, Ríos Rosas 23, 28003 Madrid, Spain

6 Department Hydrology and Geographic Information Systems, State Agency for Agriculture, the Environment and Rural Areas Schleswig-Holstein, Hamburger Chaussee 25, 24220 Flintbek, Germany

7 New Technologies for the Information Society, European Centre of Excellence, University of West Bohemia, Univerzitni 22, 30614 Plzeň, Czech Republic 
the key aspects of the interoperability to the various natural hazard communities and illustrates the applicability of the interoperability framework developed in the DS. And secondly, the paper "translates" into common language the main features and potentiality of the interoperability framework of the DS for a wider audience of scientists and practitioners in the natural hazard domain. In this paper, the four pillars of the interoperability framework will be presented. First, the adoption of a common terminology for the natural hazard domain will be addressed. A common data model to facilitate cross-domain data integration will then follow. Thirdly, the common methodology developed to express qualitative or quantitative assessments of natural hazards is presented. Fourthly, the extensible classification schema for natural hazards developed from a literature review and key reference documents from the contributing community of practice is discussed. Furthermore, the applicability of the interoperability framework for the various stakeholder groups is illustrated. This paper closes discussing main advantages, limitations and next steps regarding the sustainability and evolution of the interoperability framework.

Keywords Interoperability - Data harmonisation - INSPIRE - Natural risks · Common assessment model

\section{Introduction}

Natural hazards represent the interface between human and natural systems. From this perspective, natural hazards are part of a multidimensional domain including environmental issues, private and public sectors as well as citizens and governance ranging from local to supranational. Each natural hazard type, i.e. earthquakes, floods, landslides, is part of the wider natural hazard domain (Birkland 2006). For the scope of this paper, the natural hazard domain is considered the sphere of knowledge of the natural hazard science and practitioners and includes aspects such as hazard, risk, exposure and vulnerability.

This paper focuses on the key aspects of making data and information related to the natural hazard domain interoperable. The content of this paper stems from experience gained during the development of data specifications for the data theme Natural Risk Zones (DS) (European Commission 2013). The DS provides the technical guidelines for implementing the natural hazard data requirements lied down in the Commission Regulation for interoperability of spatial data sets and services (CEC 2013). The DS also represents an important data interoperability component for establishing an Infrastructure for Spatial Information in the European Community (INSPIRE) (CEC 2007a). The member states of the European Union (EU) are obliged to implement the data requirements by December 2015 for new data and December 2020 for existing data.

INSPIRE represents an enormous environmental data harmonisation effort at the EU level, an example of its scope is the 34 thematic domains covered and the large number of experts and organisations involved in its development (INSPIRE 2014e). The DS document is primarily the result of a multinational team of 12 experts (of which seven also authors of this paper) working together in the Natural Risk Zones Thematic Working Group (TWG-NZ). The members of the TWG-NZ, also supported by INSPIRE Data Specification Drafting Team, were selected by the INSPIRE Consolidation Team (CT) (INSPIRE 2014g) to cover not only different technical aspects of the INSPIRE data specification work (e.g. Unified Modelling Language [UML] conceptual modelling, XML- 
GML encoding), but more importantly domain-specific scientific and operational responsibility, for example, floods, geology related hazards, civil protection, forest fires, early warning. The final DS is also a result of two rounds of public consultation during which the TWG-NZ responded to around 395 comments (INSPIRE 2013a). There were also two dedicated cross-thematic workshops, attended by more than 70 European experts, whose conclusions are also reflected in the final DS. Finally, the final legal text of the Implementing Rules was a subject to the review of the EU member states representatives.

The amount of information and data necessary for comprehensive hazard and risk assessments present many challenges regarding the lack of accessibility, comparability, quality, organisation and dissemination of natural hazard spatial information. In order to mitigate these limitations an interoperability framework (IF) for natural hazard spatial data has been developed and is the basis of the DS document (European Commission 2013).

The IF has been developed following the INSPIRE Generic Conceptual Model (INSPIRE 2013b) and the common methodology (INSPIRE Drafting Team Data Specifications 2008; Toth et al. 2012). In INSPIRE, interoperability means "the possibility for spatial data sets to be combined, and for services to interact, without repetitive manual intervention, in such a way that the result is coherent and the added value of the datasets and services is enhanced" (CEC 2007a: L 108/5). Therefore, interoperability is seen as providing access to spatial datasets through the Internet. The IF provides means for facilitating access, integration, harmonisation and dissemination of natural hazard data from different domains and sources. The objective of this paper is twofold. Firstly, the paper shows the applicability of the IF and highlights the key aspects of interoperability to data users and data providers in the natural hazard domain. Secondly, the paper "translates" into common language the main features and potential of the IF for a wider audience of scientists and practitioners in the natural hazard domain but not necessarily involved in their day to day activity in spatial data interoperability issues. Additionally, the paper identifies gaps, limitations and further potential improvements in the DS.

Table 1 Pillars of the natural hazard interoperability framework

\begin{tabular}{|c|c|c|c|}
\hline \multicolumn{4}{|c|}{ Key pillars of natural hazard interoperability framework } \\
\hline $\begin{array}{l}\text { Common } \\
\text { terminology }\end{array}$ & Common data model & Common assessment model & $\begin{array}{l}\text { Common extensible } \\
\text { classifications }\end{array}$ \\
\hline $\begin{array}{l}\text { Based on } \\
\text { international } \\
\text { standards } \\
\text { (UNISDR 2009) }\end{array}$ & $\begin{array}{l}\text { Minimum set of } \\
\text { features for natural } \\
\text { hazard data } \\
\text { interoperability }\end{array}$ & $\begin{array}{l}\text { To harmonize the way of } \\
\text { expressing level or intensity, } \\
\text { likelihood of occurrence, } \\
\text { vulnerability }\end{array}$ & $\begin{array}{l}\text { For type of natural } \\
\text { hazards and category } \\
\text { of exposed elements }\end{array}$ \\
\hline $\begin{array}{l}\text { Cross-domain } \\
\text { applicability } \\
\text { (floods, forest } \\
\text { fires, etc.) }\end{array}$ & Domain extensibility & $\begin{array}{l}\text { To allow for qualitative and } \\
\text { quantitative assessment }\end{array}$ & $\begin{array}{l}\text { To facilitate } \\
\text { comparability and } \\
\text { interoperability of data } \\
\text { sets }\end{array}$ \\
\hline $\begin{array}{l}\text { Based on a } \\
\text { common data } \\
\text { sets holdings }\end{array}$ & $\begin{array}{l}\text { Covers coverage and } \\
\text { vector spatial data } \\
\text { representations }\end{array}$ & Contextual information required & $\begin{array}{l}\text { Allow also more specific } \\
\text { natural hazard types } \\
\text { from local } \\
\text { vocabularies }\end{array}$ \\
\hline $\begin{array}{l}\text { Clear and } \\
\text { unambiguous to } \\
\text { implement }\end{array}$ & $\begin{array}{l}\text { Utilizes common types } \\
\text { from INSPIRE } \\
\text { Generic Conceptual } \\
\text { Model }\end{array}$ & & \\
\hline
\end{tabular}


This paper is organised in four sections. Section 2 analyses the four pillars of the IF (Table 1): Sect. 2.1 introduces the adoption of a common terminology for the natural hazard domain (first pillar of the IF). Section 2.2 addresses the common data model (second pillar) to facilitate cross-domain data integration. In this section, we show the description and adoption of the key agreed features and their integration into the common model described using Unified Modelling Language (UML). Section 2.3 describes and defines a new common methodology (third pillar) developed to provide harmonised ways to express qualitative or quantitative assessments in the natural hazard domain such as likelihood of occurrence, level of risk. Section 2.4 describes the challenges in defining and implementing a common classification of natural hazards (fourth pillar) necessary for making data interoperable. This classification, implemented from a literature review and the open consultation, allows further additions resulting from new findings and proposals. Section 3 illustrates the applicability of the IF to example stakeholders. The last section concludes the paper discussing the main findings, challenges and limitations of the IF and addresses open issues and next steps regarding its sustainability and evolution.

\section{Natural hazard interoperability framework}

The IF represents the framework that was developed to improve the interoperability of natural hazard data. In this chapter, each of the four components of the IF is described.

\subsection{Adoption of a common terminology for the natural hazard domain}

In this section, we address the issue of a common terminology for the natural hazard domain. The domain, which is included in the data scope of INSPIRE Directive (CEC 2007a) and Commission Regulation on interoperability of spatial data sets and services (CEC 2013), covers all types of natural risks and related concepts such as their ontologies, hazard, vulnerability and exposure. Setting up a common terminology applicable in this domain was considered one of the first steps required for a consistent development of the IF. The objective was not to redefine any domain-specific concept; on the contrary, the aim was to build a common terminology from widely accepted key references.

For the scope of the IF, natural hazards are defined following the United Nations' International Strategy for Disaster Reduction (UNISDR 2009) as "natural processes or phenomena that may cause loss of life, injury or other health impacts, property damage, loss of livelihoods and services, social and economic disruption, or environmental damage". The adoption of the definitions included in the IF is the result of discussions between all actors involved (scientific community, civil protection agencies, insurance sector, decision makers, and many others), supported by national and international scientific and grey literature. The main international documents addressing natural hazards terminology that were used are: The UNISDR Terminology (UNISDR 2009), The European Commission (CEC 2010) staff working paper on risk assessment and mapping guidelines for disaster management, ISO document 31010 (ISO 2009) on risk management and risk assessment techniques, and the European Union's Directive on the assessment and management of flood risks (CEC 2007b).

The common terminology adopted fulfils two main requirements. First, it looks at wide applicability across natural hazards: floods, forest fires, landslides, etc. Second, it should represent a clear, unambiguous and consistent reference for the implementation of the 


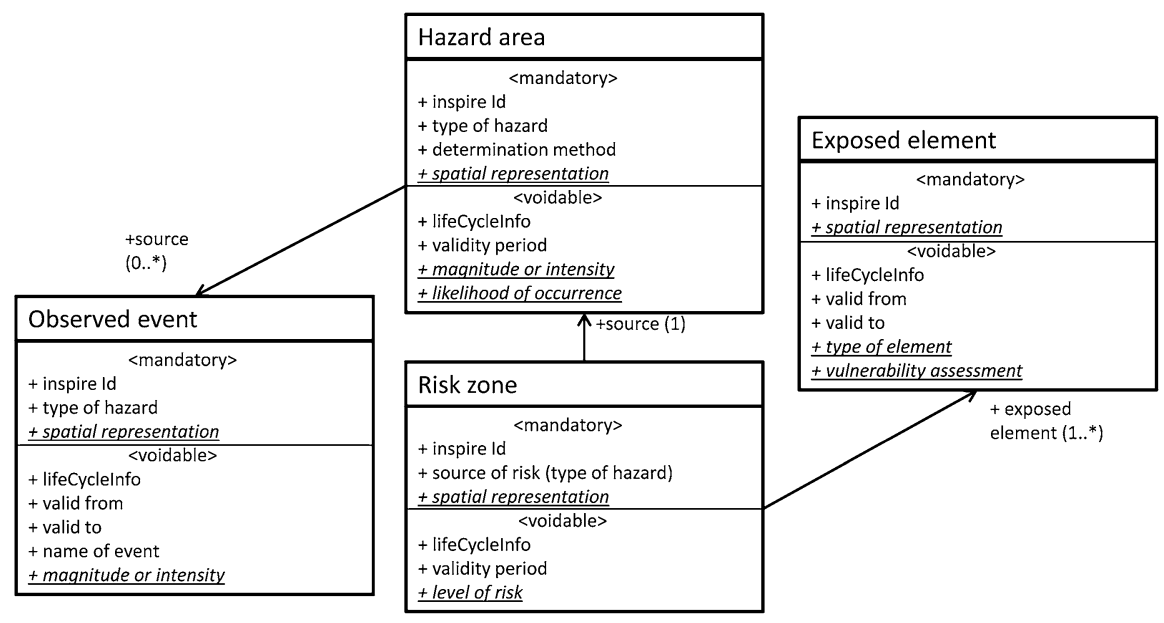

\begin{tabular}{|c|c|}
\hline \multicolumn{2}{|l|}{ Legend: } \\
\hline Risk zone: & Spatial object type that has properties; \\
\hline$<$ mandatory/voidable $>$ : & Type of obligation for data providers; \\
\hline +type of hazard: & Property of a spatial object type; \\
\hline + level of risk: & $\begin{array}{l}\text { Property of a spatial object type that is different for " coverage " and } \\
\text { " vector " version; }\end{array}$ \\
\hline$\longrightarrow+$ source $(1)$ & Logical link between spatial object types; \\
\hline$\left(0 .{ }^{*}\right),(1),\left(1 .{ }^{*}\right):$ & Multiplicity of a logical link between spatial object types. \\
\hline
\end{tabular}

Fig. 1 Simplified representation of the main classes of the UML common data model

proposed IF. The ambiguity and confusing terminology on the subject corresponds to the large number of approaches existing in the domain ranging from social sciences to hydrology, physics and geology. For instance, Aven and Renn (2010) collected up to ten different meanings accepted solely for the term risk.

The INSPIRE Directive (CEC 2007a: L 108/14) defines Natural Risk Zones as "vulnerable areas characterised according to natural hazards (all atmospheric, hydrologic, seismic, volcanic and wildfire phenomena that, because of their location, severity, and frequency, have the potential to seriously affect society), e.g. floods, landslides and subsidence, avalanches, forest fires, earthquakes, volcanic eruptions". From this perspective, and following the approach of the UNISDR (2009), risk is the consequence of hazard, exposure and vulnerability on human health, the environment, cultural and economic assets. The coexistence in space and time of these three factors causes high levels of risk for a given type of hazard. If any one of the factors increases, the amount of risk increases. Conversely, if any one of the factors reduces, so the risk reduces. A schematic description of the relationships between the concepts is shown in Fig. 1. The detailed definitions and sources adopted are in the DS (European Commission 2013) document.

\subsection{Common data model for natural hazards to facilitate cross-domain data interoperability}

The common data model also represents the key technical component of the IF. Defining a common data model to improve and facilitate cross-domain and cross-theme comparability and interoperability of natural hazards data has been the fundamental objective for 
developing the DS (European Commission 2013). In this section, we focus on explaining the main features of the model (Fig. 1), whilst a detailed description of the model is provided in the DS.

There are many obstacles to sharing heterogeneous natural hazard data across political boundaries as well as across different natural hazard types. These include: the use of different data models and terminologies representing different types of natural hazards, the use of specific local or national classification systems, the use of different data formats and data descriptions (metadata profiles) and the use of diverse coordinate reference systems. All these factors pose barriers to making data discoverable and interoperable (INSPIRE 2013b; Reichardt 2010).

The model was developed with the following considerations:

1. The definition of a minimum common set of features that standardise and formalise the best representation of spatial data properties of the natural hazard domain.

2. The model can be extended to address the specific requirements of a hazard domain (e.g. floods, landslides, etc.) whilst making the properties of the core hazard features (Fig. 1) interoperable across all types of natural hazards.

3. The model was designed to handle multiple spatial data representations.

4. The model followed generic modelling rules defined by the INSPIRE generic conceptual model (GCM) to insure basic interoperability of all 34 INSPIRE data themes (INSPIRE, 2013).

As a result of this approach, the model represents a base level of harmonisation.

\subsubsection{Description of the common data model}

The data model (Fig. 1) was developed using UML conventions and followed the agreed INSPIRE Data Specification methodology (INSPIRE 2008; Toth et al. 2012) that is based on the document EN ISO 19131 (ISO 2007). According to the methodology, the iterative process of developing the model included the following steps: use case development, identification of user requirements, as-is analysis, data specification development, gap analysis and implementation, testing and validation. The data model was developed based on:

- Forty reference documents received and analysed for user requirements [based on the survey: INSPIRE (2014f)].

- Twelve use cases developed to: (1) refine user requirements, (2) check that the final data model is applicable (European Commission 2013: Annex B).

- Three hundred and ninety-five comments received during the public consultation of the V2.0 of the data model (Cetl et al. 2012).

The simplified version of the final model (Fig. 1) presents the main classes (spatial object types) and their mutual relationships representing the four main feature types adopted. In addition to the unique object identifier (inspireID), temporal properties and geometry of the objects are also included as common types defined for all INSPIRE data themes in the INSPIRE GCM (INSPIRE 2013b). Figure 1 also shows two concepts related to the obligation of data providers to provide data relating to modelled objects which are "mandatory" and "voidable". Whereas the concept of mandatory is straightforward, the voidable concept means that for an attribute, a value of 'void' may be made available if no corresponding value is contained in the spatial data sets maintained by the member states or no corresponding value can be derived from existing values at reasonable costs. A 
reason for not providing the characteristic should be given (CEC 2013). In the next paragraphs, we describe each of the main features in abstract terms to demonstrate the scope of the model. Each feature contains properties, a set of attributes that describe data requirements for that object.

2.2.1.1 Hazard area The core properties of the UML feature type hazard area (representing, e.g. an area susceptible to flooding) are: type of hazard (using the generic natural hazard classification), determination method of the hazard, and the validity period of the hazard assessment. Other two key common properties (magnitude or intensity, likelihood of occurrence) represent the results of the quantitative or qualitative assessments of the likelihood of the event occurring (encompassing the susceptibility) and its intensity or magnitude.

The fact that often the hazard assessment is based on the analysis of already observed (historical) events is modelled as a conceptual connection (UML unidirectional association) between the hazard area and observed event (UML feature type). The unidirectional nature is due to past events being used to develop Hazard Areas not the other way around.

2.2.1.2 Risk zone The key common properties of the UML feature type risk zone (representing, e.g. a zone where a building is at risk in an area prone to earthquakes) (Fig. 1) are: source of risk, which uses the generic natural hazard classification (as described later in Sect. 2.4), validity period of the risk assessment, and level of risk described in qualitative or quantitative terms (as described later in Sect. 2.3). Each risk zone is connected (UML unidirectional association type) with at least one exposed element that is vulnerable to the type of hazard coded in the hazard area (UML unidirectional association type). These mutual logical connections are expressed in Fig. 1. The definition of a hazard area and at least one exposed element (UML multiplicity notation) is required prior to the delineation of a Risk zone.

2.2.1.3 Exposed element There are only two major required properties of the UML feature type exposed element (representing, e.g. a building or electricity substation). These are: type of element (identified in the list of categories of exposed elements in Sect. 2.4) and vulnerability assessment of the exposed element to a given hazard type.

Unlike the other feature types in the model, the situation with exposed elements is different, because these objects may already been defined in other data models under the INSPIRE framework (buildings, population distribution, public services, land cover and land use, etc.). This reflects the fact that the universe of discourse for exposed elements is very large; any spatial object of the real world can be exposed to a natural hazard. To address this issue, a concept of object referencing was applied (INSPIRE 2013b). This approach implies that an organisation (e.g. Civil Protection Authority) that provides the vulnerability assessment of exposed elements in a hazard area should reuse (using the unique inspireID) the objects from other data providers and only add the quantitative or qualitative results of their vulnerability assessments (e.g. affected people, affected buildings, economic losses, etc.).

When the vulnerability assessment provider defines a unique spatial location (e.g. geometry of the Exposed element based e.g. on statistical analysis) then they should provide them. 
2.2.1.4 Observed event The UML feature type observed event (representing e.g. a historical windstorm) is modelled as a feature type which has similar properties as the hazard area feature type, except that it has a name (e.g. storm Kyrill), has no validity period nor likelihood of occurrence as it is a past event and not a future scenario and has no determination method. The magnitude or intensity attribute is suitable for recording the severity of the past event. This can be expressed in many ways according to the data available regarding the consequences (damage) of the event.

2.2.1.5 Spatial representation Results of the as-is analysis and the public consultation (Cetl et al. 2012) indicate that data in the natural hazard domain is represented by both vector and coverage data formats. As an example, flood water depth is usually represented as continuous (coverage) data and buildings as exposed elements represented as discrete (vector) data. Therefore, all four core feature types defined in the data model could be mapped using both spatial representations. In the data model, the discrete features are described using the framework of EN ISO 19107 norm (ISO 2003) and continuous features using the framework of ISO EN 19123 (ISO 2005).

\subsection{Common natural hazard assessment model}

Defining a common model for qualitative and quantitative assessment in the natural hazard domain is an important pillar of the IF. The term "assessment" is understood as an evaluation and is in the IF used to describe the level of intensity or magnitude of a hazard phenomenon, the likelihood of occurrence of a hazard, or the level of vulnerability of an exposed element to a hazard. It is hard to track and map all existing measures and scales that can potentially be used in order to report those notions. Therefore, we defined the common components of an assessment that facilitates the comparison of the results.

The common model was developed in three steps. Firstly we identified and detailed possible types of assessments of the core terms (observed event, hazard area, risk zone and exposed elements). In the second step, we analysed whether the selected type of assessments could be applicable to all types of natural hazards. And in the final step, we developed a common model (Fig. 2) for providing results of the each type of selected assessment.

The common assessment model provides means for qualitative and quantitative evaluations. In both cases, qualitative or quantitative assessment results, the provision of the "background" contextual information - the methodological framework the evaluation was made within - is a fundamental principle. The reference to the methodology used for an assessment is obligatory information that uses a reference data model (DocumentCitation) common to all INSPIRE data themes (INSPIRE 2013b). When there is a qualitative assessment (e.g. when the level of risk is reported as being "high"), the common assessment data model uses a "character string" data type (free text). The quantitative assessment is expressed as a numeric value plus a unit of measure. Several assessments for the same event can be provided.

Below, we detail how the common assessment model is applied to the four core feature types of the IF:

\subsubsection{Hazard areas}

Likelihood of occurrence and magnitude or intensity was identified as key common assessments of natural hazards. The likelihood of occurrence refers to the chances of an 


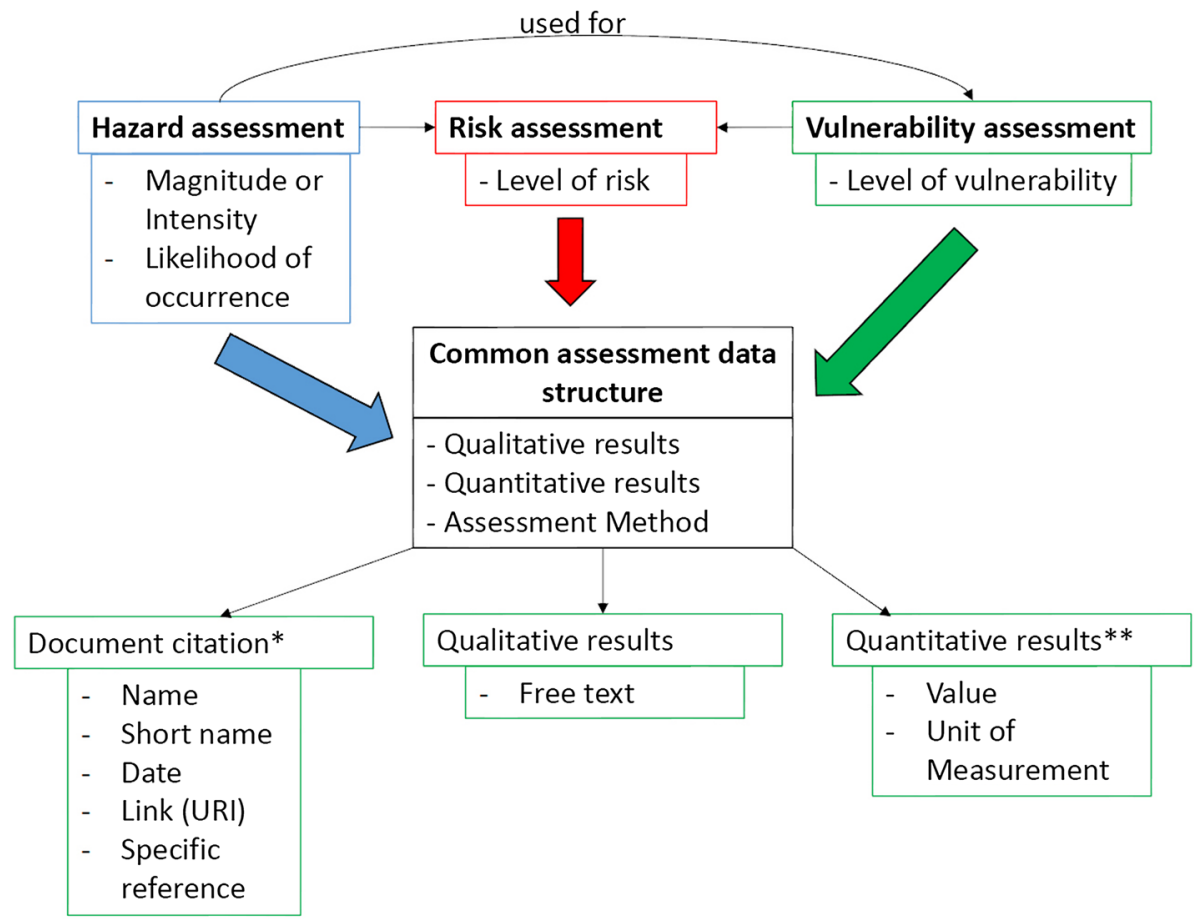

*Also used for reference to legislation; ** For Likelihood of occurrence: Validity period and Probability

Fig. 2 Common natural hazard assessment model

event occurring. When expressed quantitatively, the likelihood of occurrence can be expressed either as a return period (which is especially used by the floods and earthquake community) or more generically as a probability or a frequency. The likelihood of occurrence also encompasses the notion of susceptibility, which is widely used in, e.g. the landslide community, referring to a relative probability of poorly known chances or without addressing chances from a numerical perspective.

The way notions of intensity or magnitude of a natural hazard are modelled allow a broad use by the natural hazard community: the magnitude or intensity can either encompass flood water heights (Magnitude: in metres), water discharge (Intensity: cubic metres per seconds), a value within the Richter (Magnitude: rupture energy) or the Mercalli (Intensity: surface effects of an earthquake) scale, or a volume of materials moved by a landslide (Magnitude: cubic metres).

\subsubsection{Observed event}

The severity of a past event is the key notion for evaluation. This can be expressed in many ways, according to available data: a number of dead or injured people, an amount of destroyed houses, an amount of money that expresses the damage of an event, a combination of effects, etc. This notion is in line with what is considered as intensity or magnitude of a natural hazard; therefore, the "qualitative/quantitative assessment" data model can be used. 


\subsubsection{Risk zone}

The level of risk is an evaluation of the combination of potential consequences of an event and the associated probability/likelihood of the occurrence of the event. Usually, the risk assessment can be addressed in different ways by a data producer. Therefore, it is believed that the use of a common assessment data model is a flexible option.

\subsubsection{Exposed elements}

The key property of an exposed element is its vulnerability to a type of natural hazard. The vulnerability of an exposed element depends on the type of hazard and its magnitude or intensity, as well as the properties of the feature itself (physical, or not, individually or collectively, etc.). Once those properties are set, the level of vulnerability can be calculated, or assessed using the quantitative or qualitative assessment model.

\subsection{Common extensible classification schemas for natural hazards}

In this section, we address first the generic extensible classification of natural hazards and second the generic classification of exposed elements. Both classifications and their definitions are accessible online from the central INSPIRE registry (INSPIRE 2014b) under the INSPIRE data theme Natural Risk Zones in a form of code lists with defined values.

\subsubsection{Extensible classification of natural hazards}

Classifying natural hazards is a difficult task due to the complexity of the processes involved and relations that a hazard phenomenon poses within the human system with which it interacts. It usually implies professional competency disputes (Olcina and Ayala 2002) which can be seen as another symptom of how varied can a hazard be seen and studied. Most classifications used so far are objective driven or very specific, e.g. disaster databases for insurance companies, landslide studies, and none of them proved to be flexible enough for interoperable means due to the presence of duplicated or void categories, thematic bias, or other more complex issues such as chained consequences or multitype concurrent hazards. Providing a classification aims at easing the process of cataloguing data and facilitating interoperability, by identifying the most used and accepted terminology in the highest levels. Olcina and Ayala (2002) identified up to eight main approaches to classify hazards, such as its origin, type, environmental location, foreseeability, activity level, duration, action radius and damage vector. The origin- or type-driven classifications are by far the most widely spread and used; therefore a classification of origin or type was suggested by the TWG and agreed after public consultation. Still, many similar processes in its type and study method can be initiated after many different natural scenarios (e.g. a tsunami can be caused by a landslide, an earthquake and a volcanic explosion), and many processes demonstrate unclear boundaries between themselves. For example, a mud flow can be considered as a type of landslide, a type of flood or a type of hazard driven by volcanic activity. Terminology of a very similar process in its nature can differ according to the environmental setting where it develops, e.g. a mud flow is also called lahar if it is volcanic driven. The specificity of the terms can be very relevant for the communities or individuals studying natural hazards because it adds a context that 
might condition other properties related or not to the process itself (e.g. mud composition, thermal anomalies in the surrounding areas, geomorphological settings, etc.). A two-level simple and extensible hazard type classification was adopted in the DS that in the model is supplemented with an open option to provide an additional classification term that addresses specific hazard types not included in the classification. The hazards classification is by no means exhaustive. Nevertheless, it includes an extensive list of hazards. In addition, the provision of more detailed hazard types is facilitated and highly recommended. The complete classification proposed is available in Annex C of the DS (European Commission 2013) and online in the INSPIRE registry (INSPIRE 2014b).

There are two options for extending the classification (Fig. 3). First, it is possible to extend the classification with a narrower term to those that are provided: this can be done by the data provider, for as much as he refers to an existing term of the classification as "parent" of the term he enters into the classification. This step (picking an existing term, or extending the classification with a new term, and in the meantime referring to an existing one) is mandatory to any data provider. Therefore, a unique classification was adopted as the backbone to which any term describing a type of natural hazard must be attached, and thus enabling interoperability between different datasets. The second option is specifying a new term. Thus, it is feasible for a data provider to add a specific new term that is not in the classification or for which not a single parent term can be found. In such a case, the data provider is allowed to provide his specific term, but he should also provide a link (set as a URI) where one could find more information about the value entered. This latter possibility is not a bypass to the natural hazard classification, to which a reference must be made anyhow: it is considered as an additional possibility to provide further information about the nature of the natural hazard type entered.

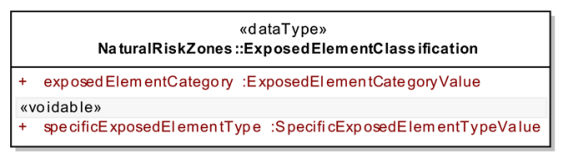

Legend

tags (values): Metadata about the type

<<dataType >: UML stereotype

<<dataType >>: UML stereotype
<codeList»>: UML stereotype
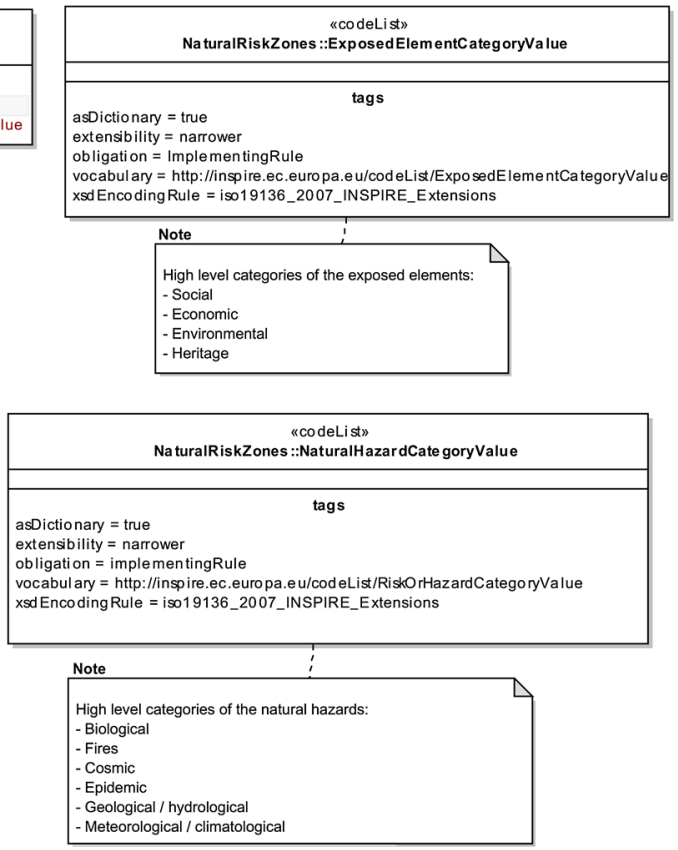

Fig. 3 UML representation of the natural hazard classification information 


\subsubsection{Extensible classification of exposed elements}

To facilitate comparability of the results of risk analysis, a concept of "category of exposed element" under which exposed elements are considered was designed (Fig. 3). This generic list of terms provides information about the nature of the exposed element. The complete proposed list, which is also extensible by data providers, is available in Annex C of the DS (European Commission 2013) and online in the INSPIRE registry (INSPIRE 2014a). It has to be noted that the same geographical feature considered as exposed element can actually be seen from different points of view: a historical city hall can be considered at the same time a building open to people, as a historical heritage feature, or even as a potential location of headquarters during crisis management. In this example, the decision to which category the building should be allocated is taken during the implementation of the assessment model; hence, it is to be taken by the organisation in charge of it. However, the feature (building in this case) is part of the exposed elements collection thus enabling interoperability.

\section{Applicability of the interoperability framework}

This chapter illustrates the applicability of the IF in three steps: first, applying the framework to a selected EU-wide information system. Second, summarising existing EU projects that use the IF or part of it. And finally, evaluating the input from the public consultation conducted during the development of the DS (European Commission 2013) and reporting the submission of natural hazard national data sets to the INSPIRE GeoPortal (INSPIRE 2014c) to date.

\subsection{Data services provided by the European Forest Fire Information System (EFFIS)}

This section illustrates the application of the IF by using examples of data services provided by the European Forest Fire Information System (EFFIS). The European Commission has developed the EFFIS (2014) as the focal point for information on forest fires addressing fire prevention, fire fighting and post fire evaluation. EFFIS includes, among other modules, web mapping services (WMS) for the provision of meteorological fire danger maps (hazard area) and fire perimeter maps of burnt area (observed event) during the fire season. The fire danger service is used in this section for showing the applicability of the IF.

Fire danger (hazard) is defined as the probability that a fire with a given intensity ignites and propagates. However, most short-term fire danger systems, as EFFIS, assess fire danger using numerical indices not producing a probability per se. A fire danger index can be defined as a quantitative indicator of one or more facets of fire danger, expressed in a relative sense or as an absolute measure (Merrill and Alexander 1987). An example is the Fire Weather Index (FWI) (Van Wagner 1987) from the Canadian Forest Service adopted in EFFIS. The FWI consists of six components that account for the effects of fuel moisture and wind on fire behaviour.

In EFFIS internal workflow, meteorological data and remotely sensed MODIS satellite imagery are acquired during the fire season for computing several fire indicators and statistics. Meteorological data from three providers is used for producing up to 8 days forecasted fire danger maps on a daily basis. MODIS imagery is used to map burned areas 
with 250-m spatial resolution. Daily imagery from MODIS satellites is acquired and processed few hours after the acquisition by MODIS. EFFIS provides the daily update of the perimeter of burnt areas for fires of about 40 ha or larger. Fire danger (hazard) maps and fire perimeter maps are provided in EFFIS via map viewer and WMS (Fig. 4).

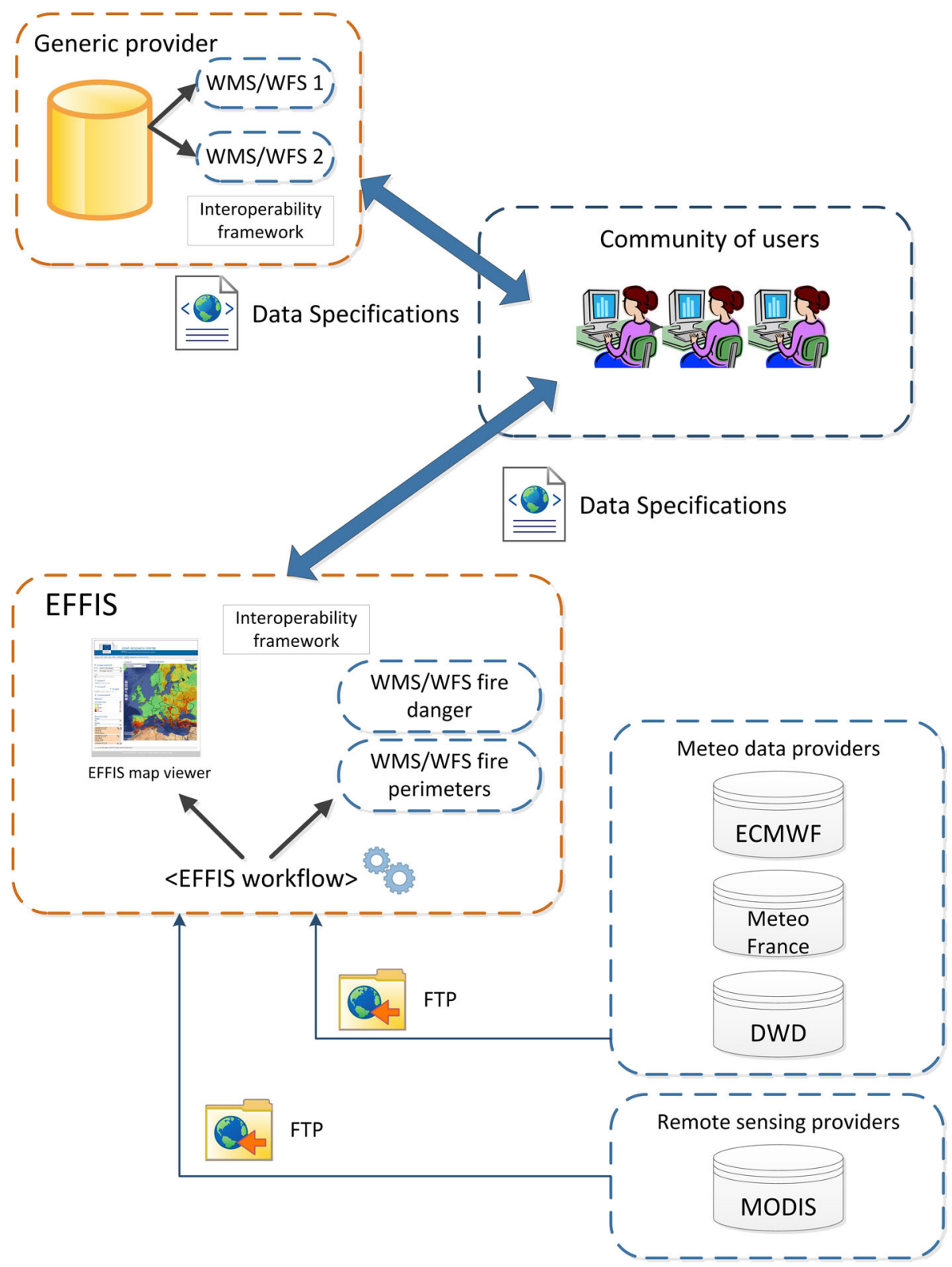

Fig. 4 Mapping services provided by the European Forest Fire Information System (EFFIS) in the frame of the interoperability framework (IF) for natural hazard spatial data 
As indicated in Fig. 4, the implementation of the IF will provide means for making EFFIS data delivered using WMS service interoperable with data from other data providers. The generic provider in Fig. 4 can supply different data typologies of interest for fire emergency services such as for example probabilistic national and regional level fire hazard or exposure data (e.g. properties, wood resources, protected areas, power networks, land cover, etc.) in high fire danger zones defined by the EFFIS danger map.

The information required for making data interoperable is represented in Fig. 4 as "Data Specifications" files that include all the features of the IF described in Sect. 2. The "Data Specifications" include all the properties defined in the DS that fulfil the requirements of the IF of Fig. 1 and the common classifications of Fig. 3. A sample of the common properties required for the case of the fire danger map is shown in Table 2. Assuming that both EFFIS and the generic provider of Fig. 4 fulfil the IF requirements, then it is assumed that data sets from EFFIS and the generic provider are interoperable and accessible by the community of users without further data manipulation. Table 2 shows the main feature types of the IF that were defined in the DS document. The type of Hazard area is set using the code list described in Sect. 2.4, in the case of the EFFIS fire danger data set is " $<$ forest fires $>$ ". The determination method describes the method used for delineating the hazard, i.e. modelling or indirect determination. The spatial representation was coded as "Grid" because the data set provided is a raster map. And finally, the likelihood of occurrence describes the chance of an event occurring, in this case measured in a qualitative scale of six levels of fire hazard. The specifications described are key for making data sets from different providers interoperable and easily accessible. The increasing number of providers fulfilling the requirements of the IF will ease integrating natural hazard data from different sources into a common framework promoting enhanced interoperability.

\subsection{Implementation examples: projects}

Several European Commission-funded projects incorporating aspects of the natural hazard domain of study have reported findings in implementing the DS since their publication. These are summarised in Table 3. None of the projects have implemented the full model, and none to this stage have extended the final published conceptual model for their purposes, rather the terminology to include different languages or translate terms between languages.

The Life + Imagine project went furthest in implementing the model; like the PICRIT project, they identified a requirement for their purposes to extend the landslide hazard terminology to differentiate between different styles of landslides, and this is made possible through the extensible code list that is made available. The PICRIT project also identified issues relating to scale; whilst discussing the development of the model, it was agreed that these were of lower priority than providing a base-level platform. Scale issues should be looked at through the official EC INSPIRE Maintenance and Implementation Framework (MIF) (INSPIRE 2014d) in the future as they are likely to be common to several INSPIRE domains. The PanGeo project team were a stakeholder in the development of the DS, they used an early version of the model released in the first year of TWG tasks. The project team extended the concept of a hazard determination method to enable reproducibility of the project methodology in delineation of hazard areas. PanGeo identified that complexity of interpreting UML as a modelling language was a potential barrier to use. Clearly, the full model will be tested further as more data sets are published in the coming years following the INSPIRE legislation requirements. 
Table 2 Properties of the forest fire danger data according to the data model of the interoperability framework (IF)

\begin{tabular}{|c|c|c|}
\hline Properties & Description & $\begin{array}{l}\text { Attributes and their values for the fire } \\
\text { danger data }\end{array}$ \\
\hline $\begin{array}{l}\text { Identifier } \\
\quad \text { (inspireID) }\end{array}$ & $\begin{array}{l}\text { The "inspireID" shall be a persistent external } \\
\text { object identifier. The inspireID consists of two } \\
\text { mandatory and one optional attribute: "localID", } \\
\text { "namespace" and "versionID". This structure } \\
\text { provides a unique and consistent identification } \\
\text { schema enabling multiple non-spatial resources } \\
\text { to be linked to the same object }\end{array}$ & $\begin{array}{l}\text { localID: } \\
\text { <FWIECMWF050820140708201401.tif }> \\
\text { Namespace: } \\
\text { <EC.JRC.EFFIS }> \\
\text { versionID: } \\
\text { <05082014.01> }\end{array}$ \\
\hline Type of hazard & $\begin{array}{l}\text { This property is represented by a } \\
\text { "NaturalHazardClassification" scheme which } \\
\text { contains an attribute pointing to the code list } \\
\text { "NaturalHazardCategoryValue" and an attribute } \\
\text { that refers to the empty code list: } \\
\text { "SpecificHazardTypeValue" }\end{array}$ & $\begin{array}{l}\text { NaturalHazardCategoryValue: } \\
<\text { Forest fires }> \\
\text { SpecificHazardTypeValue: } \\
<\text { unpopulated }>\end{array}$ \\
\hline $\begin{array}{l}\text { Determination } \\
\text { method }\end{array}$ & $\begin{array}{l}\text { There are several ways to delineate the perimeter } \\
\text { of a hazard: to compute it according to a model } \\
\text { or to define it by interpretation of available data } \\
\text { and/or information. Two possible values: } \\
\text { "modelling" or "indirect determination" }\end{array}$ & $\begin{array}{l}\text { determinationMethod: } \\
<\text { Modelling }>\end{array}$ \\
\hline $\begin{array}{l}\text { Life span of the } \\
\text { object }\end{array}$ & $\begin{array}{l}\text { The date the object was entered in the dataset and } \\
\text { the date the object was removed or superseded } \\
\text { from the dataset. Dates are represented in the } \\
\text { attributes "beginLifeSpanVersion" and } \\
\text { "endLifeSpanVersion" }\end{array}$ & $\begin{array}{l}\text { beginLifeSpanVersion: }<05 / 08 / 2014> \\
\text { endLifeSpanVersion: }<06 / 08 / 2014>\end{array}$ \\
\hline Validity period & $\begin{array}{l}\text { It is the future finite time frame where the hazard } \\
\text { applies }\end{array}$ & $\begin{array}{l}\text { validityPeriod: } \\
<\text { for } 1 \text { day }>\end{array}$ \\
\hline $\begin{array}{l}\text { Spatial } \\
\quad \text { representation }\end{array}$ & $\begin{array}{l}\text { The method used to spatially represent } \\
\text { geographical information }\end{array}$ & $\begin{array}{l}\text { spatialRepresentation: } \\
<\text { Grid }>\end{array}$ \\
\hline $\begin{array}{l}\text { Magnitude or } \\
\text { intensity } \\
\text { (rangeSet) }\end{array}$ & $\begin{array}{l}\text { The magnitude or intensity of a hazard can be } \\
\text { expressed either qualitatively or quantitatively. } \\
\text { The data type "LevelOrIntensity" is defined by a } \\
\text { set of three properties: 1) A qualitative value; 2) } \\
\text { A quantitative value described as a measure (that } \\
\text { is to say a number and a unit); 3) A reference to } \\
\text { the method in which further information can be } \\
\text { obtained }\end{array}$ & $<$ Unpopulated $>$ \\
\hline $\begin{array}{l}\text { Likelihood of } \\
\text { occurrence } \\
\text { (rangeSet) }\end{array}$ & $\begin{array}{l}\text { The likelihood of occurrence can be expressed } \\
\text { either qualitatively or quantitatively. It is a } \\
\text { concept relating to the chance of an event } \\
\text { occurring. The structure of the data type } \\
\text { "LikelihoodOfOccurrence" is the same as used } \\
\text { for Magnitude or intensity, and includes a } \\
\text { reference to the "AssessmentMethod" } \\
\text { (DocumentCitation defined by: Name, Short } \\
\text { name, Date, Link [URI] and Specific reference) }\end{array}$ & $\begin{array}{l}\text { qualitativeValue: } \\
\text { <unpopulated> } \\
\text { quantitativeValue: } \\
\text { Value: } \\
\text { < fire danger level> } \\
\text { UnitOfMeasure: } \\
\text { <index > (fire danger index) } \\
\text { DocumentCitation: } \\
\text { Name: } \\
\text { <Development and structure of the Canadian } \\
\text { Forest Fire Weather Index System }> \\
\text { Date: } \\
<1987> \\
\text { URI: <http://cfs.nrcan.gc.ca/pubwarehouse/pdfs/ } \\
\text { 19927.pdf }> \\
\text { SpecificReference: } \\
<\text { Van Wagner, C.E., 1987. Development and } \\
\text { structure of the Canadian Forest Fire Weather } \\
\text { Index System. Canadian Forestry Service, } \\
\text { Headquarters, Ottawa. Forestry Technical } \\
\text { Report, 35. 35 pp> }\end{array}$ \\
\hline
\end{tabular}




\subsection{INSPIRE GeoPortal statistics of public consultation and testing}

From July till October 2011, the official public consultation and testing of the INSPIRE data specifications took place, see Cetl et al. (2012) or comments and resolutions of the stakeholder consultation in the so-called resolution table (INSPIRE 2011). For the data theme Natural Risk Zone which IF is an essential part, 374 comments were received as well as three testing reports. Four major categories of comments were identified. These were related to: (1) clarification and consistency of the general terminology used for the key terms; (2) both proposed classifications (i.e. the type of natural hazards and type of exposed elements); (3) both spatial representation types (vector and coverages); and (4) how to provide information on past events. Based on the detailed analysis of the comments and testing reports, the final data model of the IF was produced in three steps. First, clarifying the used terminology by applying the standard UNISDR (2009), second introducing the feature type observed event in the data model, and finally by applying the extensibility concept for both key classifications and providing means for both spatial data representations.

The INSPIRE directive requires the commission to establish a community geo-portal, and the member states shall provide access to their infrastructures through the geo-portal as well as through any access points they themselves decide to operate. The INSPIRE geoportal (INSPIRE 2014c) published in December 2011 is becoming the central point of access to geospatial data in Europe. Currently, it provides access to over 225,000 metadata records about datasets or services. There are currently 516 metadata records about datasets/ services related to natural risk zones.

\section{Discussion and conclusions}

A multidisciplinary interoperable approach for natural hazards is a key instrument for disaster-risk reduction (United Nations 2005). The amount of spatial data available necessitate a framework for fully exploiting the potential for decision-making in the natural hazard domain. This covers all the phases of the disaster cycle, from prevention and preparedness to disaster recovery. Defining a common framework for making data interoperable is a key component of the instrument.

The main results of this paper are the illustration of the key aspects of the IF for natural hazards and the assessment of its applicability in different contexts. The results confirm that the IF is flexible and can be applied in the natural hazard domain facilitating harmonisation of multi-source datasets and making them comparable and ready for crossdomain assessments.

In this paper, the IF has been illustrated in the field of forest fires. In addition in the DS, a series of use cases, e.g. landslides and floods, are included with the twofold scope of, first to define the data scope of the IF, and second to test the applicability of the final data model. The data model represents the core that can be implemented and extended by domain-specific requirements.

The IF also represents an attempt to streamline communication between natural risks management authorities and natural hazard data providers. Having relevant information regarding natural risks, e.g. potential impacts, spatial extent, vulnerable exposed elements, is necessary for disaster-risk reduction.

The common model for expressing quantitative and/or qualitative results of the assessments is seen as one of the key pillars of the proposed IF. It does not impose any concrete methodology, something not realistic due to the diversity of the natural hazard 


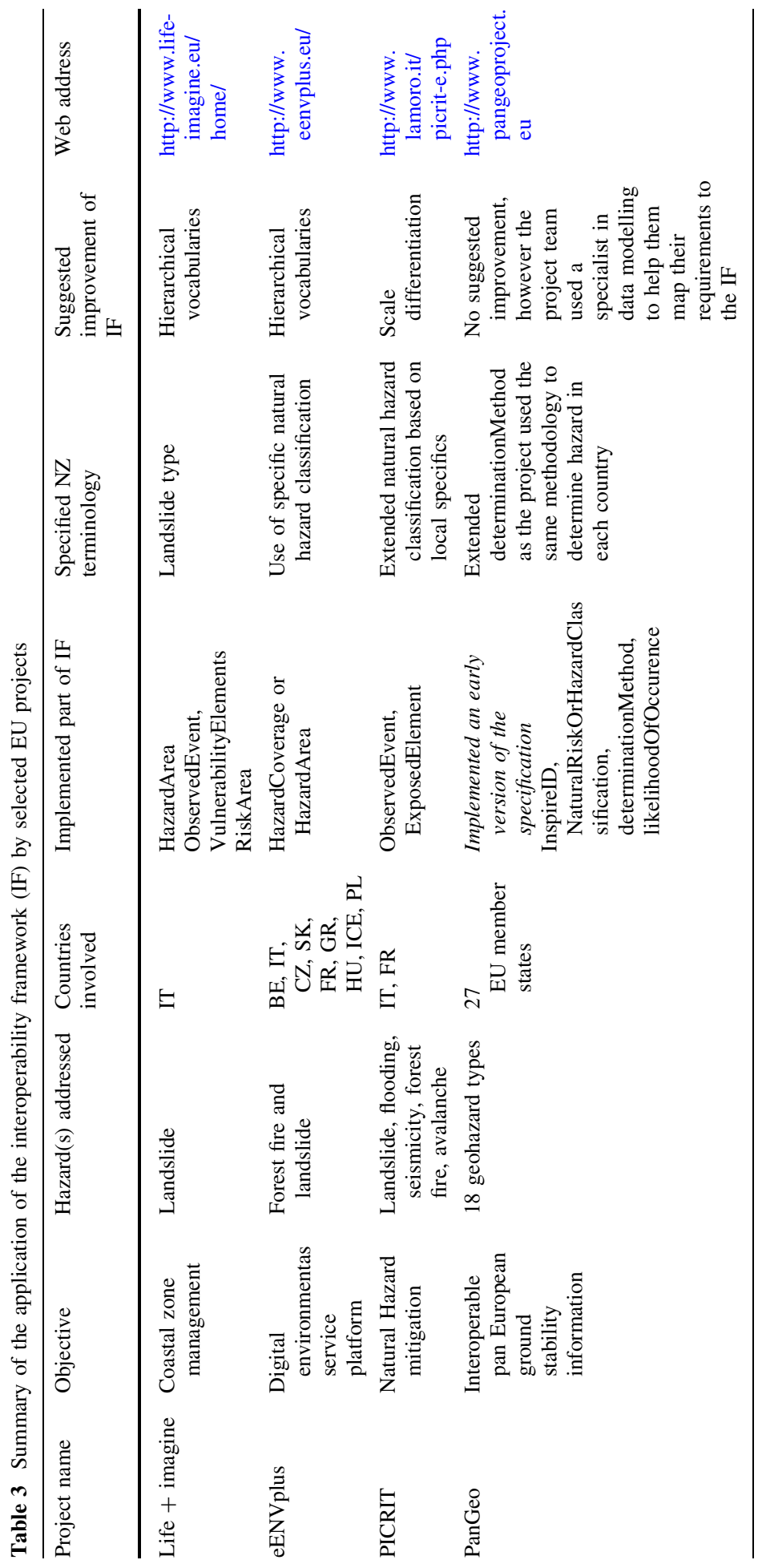


domain, but it provides a harmonised structure for data users to identify and access critical information such as the return period or magnitude of event as well as links to additional contextual information about methods, instruments used. For data providers, this model gives a harmonised structure for data dissemination.

Another pillar of the IF is the classification of natural hazards and exposed elements using a common terminology. This gives users freedom to address the specific types of natural hazards, whilst it does not lower interoperability objectives.

It is acknowledged that the proposed IF has been developed to provide common forms for all types of natural hazards. However, the multiplying effects of interlinked natural hazards have yet to be addressed. On the other hand, if the IF is successfully implemented by EU member states natural hazard data providers (by 2015/2020), the amount of available interoperable data sets will increase promoting multidisciplinary understanding and leading to improved disaster-risk reduction. Additionally, a more detailed model to capture delineation methodologies for defining hazard areas is currently not present in the IF, as identified by the PanGeo project. This might be seen as a limitation of the IF. However, it has had the effect that the model is simpler, hence has greater interoperability. The potential complexity related to hazard determination could be a subject for thematic extensions for specific natural hazards.

Another point which is outside the scope of the IF model is scaling of spatial data. From the perspective of the IF, data users are responsible for evaluating the applicability of available data resources accessible using the IF. An example is the data on forest fires danger as described in Sect. 3.1 where fire danger spatial data sets are provided at 10-, 16and $25-\mathrm{km}$ grid cell sizes. Integrating this data with, for instance, exposed elements data at higher spatial resolutions could violate some assumptions of spatial analyses.

The sustainability of the model is supported by the legally binding character of INSPIRE in which the IF was developed. However, sustainability will depend on its actual use since the real benefits of any Spatial Data Infrastructure are materialised only when the whole infrastructure is fully implemented (Craglia and Campagna 2010). Since the IF belongs to the domain of thematic data infrastructures, its benefits will also be visible once implemented and used. Another factor that is important from the sustainability point of view is the adoption of the IF by specific natural hazard stakeholders and its extension to address any scientific needs.

Acknowledgments The authors would like to thank their host organisations for funding their involvement in the TWG-NZ and the Joint Research Centre of the European Commission for facilitating and hosting the process and outcomes. We would like also to thanks the anonymous reviewers for useful suggestions during the review process. The authors would also like to thank other members of the TWG-NZ: Raquel Canet Castella, George Exadaktylos, Cristiano Giovando, Andrea Camia and Venco Bojilov.

Open Access This article is distributed under the terms of the Creative Commons Attribution 4.0 International License (http://creativecommons.org/licenses/by/4.0/), which permits unrestricted use, distribution, and reproduction in any medium, provided you give appropriate credit to the original author(s) and the source, provide a link to the Creative Commons license, and indicate if changes were made.

\section{References}

Aven T, Renn O (2010) Risk management and governance: concepts, guidelines and applications, vol 16. Risk, governance and society. Springer, Berlin. doi:10.1007/978-3-642-13926-0_1

Birkland TA (2006) Lessons of disaster: policy change after catastrophic events. American Governance and Public Policy Series, Georgetown University Press, Washington, DC 
CEC (2007a) Directive 2007/2/EC, of 14th March, establishing an infrastructure for spatial information in the European Community (INSPIRE). Off J Eur Union 24(5):2007

CEC (2007b) Directive 2007/60/EC of the European Parliament and of the Council of 23 October 2007 on the assessment and management of flood risks. Off J Eur Union 6(11):2007

CEC (2010) SEC(2010)1626 final: Commission Staff Working Paper on Risk Assessment and Mapping Guidelines for Disaster Management, Commission of the European Communities, Brussels, 21.12. 2010

CEC (2013) Commission Regulation (EU) No. 1253/2013 of 21 October 2013 amending Regulation (EU) No. 1089/2010 implementing Directive 2007/2/EC as regards interoperability of spatial data sets and services. Official Journal of the European Union 10(12):2013

Cetl V, Tuchyna M, Nunes De Lima MV, Tóth K, Lutz M, Smits P (2012) INSPIRE Annex II and III themes testing and consultation summary. Joint Research Centre, JRC Scientific and Policy Reports, 42

Craglia M, Campagna M (2010) Advanced regional SDI in Europe: comparative cost-benefit evaluation and impact assessment perspectives. Int J Spat Data Infrastruct Res 5:145-167

EFFIS (2014) European Forest Fire Information system (EFFIS) http://forest.jrc.ec.europa.eu/effis. Accessed 31 Jan 2014

European Commission (2013) Data specification on Natural Risk Zones-technical guidelines. European Commission, Joint Research Centre, D2.8.III.12_v3.0, 135

INSPIRE (2008) Drafting team "data specifications" methodology for the development of data specifications, INSPIRE drafting team "data specifications", 123

INSPIRE (2011) Stakeholder consultation 2011 resolution table. http://inspire.ec.europa.eu/documents/ Data_Specifications/Stakeholder_Consultation_2011_Resolution_Table.xlsx. Accessed 30 June 2014

INSPIRE (2013a) Consultation results - INSPIRE data specifications Annex II and III Comments and resolution. INSPIRE. http://inspire.jrc.ec.europa.eu/documents/Data_Specifications/Stakeholder_ Consultation_2011_Resolution_Table.xlsx. Accessed 01 Dec 2013

INSPIRE (2013b) D2.5: Generic conceptual model, version 3.4, INSPIRE drafting team "data specifications", 152

INSPIRE (2014a) Exposed element category. http://inspire.ec.europa.eu/codelist/ExposedElementCategory Value/. Accessed 31 Jan 2014

INSPIRE (2014b) INSPIRE code list register. http://inspire.ec.europa.eu/codelist/. Accessed 31 Jan 2014

INSPIRE (2014c) INSPIRE GeoPortal. http://inspire-geoportal.ec.europa.eu/. Accessed 30 June 2014

INSPIRE (2014d) INSPIRE maintenance and implementation. http://inspire.ec.europa.eu/index.cfm/pageid/ 5160. Accessed 31 Jan 2014

INSPIRE (2014e) INSPIRE stakeholders. http://inspire.ec.europa.eu/index.cfm/pageid/181. Accessed 31 Jan 2014

INSPIRE (2014f) User requirements survey. http://inspire.ec.europa.eu/index.cfm/pageid/601. Accessed 31 Jan 2014

INSPIRE (2014 g) Who's who in INSPIRE. http://inspire.ec.europa.eu/index.cfm/pageid/481. Accessed 31 Jan 2014

INSPIRE Drafting Team Data Specifications (2008) Drafting team "data specifications" methodology for the development of data specifications, INSPIRE, 123

ISO (2003) ISO 19107 geographic information-spatial schema, ISO, 166

ISO (2005) ISO 19123 geographic information-Schema for coverage geometry and functions, ISO, 65

ISO (2007) ISO 19131 geographic information-data product specifications, ISO, 40

ISO (2009) ISO 31010 Risk management—risk assessment techniques, ISO, 176

Merrill DF, Alexander ME (1987) Glossary of forest fire management terms. Canadian Committee on Forest Fire Management, National Research Council of Canada, ON Pub. NRCC No. 26516, Ottawa, 91

Olcina J, Ayala FJ (2002) Riesgos Naturales. Conceptos fundamentales y clasificación, Ariel, 1512

Reichardt M (2010) Open standards-based geoprocessing Web services support the study and management of hazard and risk geomatics. Nat Hazards Risk 1:171-184

Toth K, Portele C, Illert A, Lutz M, de Lima MN (2012) A conceptual model for developing interoperability specifications in spatial data infrastructures. European Commission - Joint Research Centre, EUR 25280 EN, Publications Office of the European Union, Luxemburg, 62

UNISDR (2009) 2009 UNISDR terminology on disaster risk reduction. United Nations International Strategy for Disaster Reduction (UNISDR), Geneva, 30

United Nations (2005) Hyogo framework for action 2005-2015: building the resilience of nations and communities to disasters. UN - International Strategy for Disaster Reduction, A/CONF. 206/6, United Nations, Hyogo, Japan, 22

Van Wagner CE (1987) Development and structure of the Canadian Forest Fire Weather Index System. Canadian Forestry Service, Forestry Technical Report, 35, Headquarters, Ottawa, 37 